\title{
$<$ 기술논문>
}

\section{휘발유 차량에서 배출가스에 미치는 올레핀의 영향 \\ 박 천 규$^{1,2)}$. 정 충 섭 ${ }^{1)} \cdot$ 나 병 기리 \\ 한국석유관리원 석유기술연구소 ${ }^{1)}$ - 충북대학교 화학공학과 ${ }^{2}$}

\section{The Effect of Olefin Contents on Exhaust Emissions from Gasoline Vehicles}

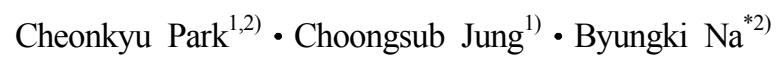

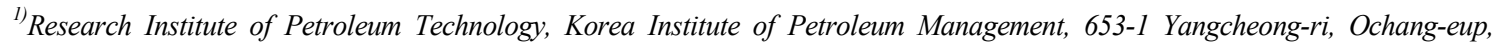 \\ Cheongwon-gun, Chungbuk 363-883, Korea \\ ${ }^{2)}$ Department of Chemical Engineering, Chungbuk National University, Chungbuk 361-763, Korea
}

(Received 18 June 2013 / Revised 29 August 2013 / Accepted 3 September 2013)

\begin{abstract}
Exhaust emissions were studied as a function of gasoline olefin composition in two vehicles-MPI and GDi engine equipped vehicles. Three different gasolines were tested which varied in olefin contents-12, 16 and 20 vol\%. Exhaust emissions in two vehicles were affected by changes in gasoline olefin composition. Responses to changes in olefins were similar in both vehicles : reducing olefins lowered emissions of NOx and CO. Measured exhaust emissions included total hydrocarbons (THC), oxides of nitrogen (NOx), carbon monooxide(CO), carbon dioxide $\left(\mathrm{CO}_{2}\right)$, formaldehyde, benzene, toluene, xylene, 1,3-butadiene and acetylene.
\end{abstract}

Key words : Gasoline(휘발유), Olefin(올레핀), Emission(배출)

\section{1. 서 론}

우리나라는 급격한 산업발전을 통해 자동차의 도 입이 증가되면서 대도시의 대기환경오염이 가시화 되어졌다. 이를 해결하기 위한 방안으로 1990년 대 기환경보전법 개정을 통해 그동안 자동차 성능을 충족하기 위해 관리해 왔던 자동차 연료품질기준을 대기 오염물질 저감을 위한 자동차 배출허용기준 차원에서 접근하기 시작하였다. ${ }^{1,2)}$ 이로써 1991년부 터 연료로부터 기인되는 오염물질 저감을 위해 자 동차용 휘발유와 경유에 적용되는 품질기준을 규정 하였다.

전체적으로 연료의 기준항목은 국내 대기오염의 추세 및 외부 환경여건 변화에 따라 발전해 오고 있 다. 그러나 실질적으로 자동차에서의 오염물질 저 감과 연계된 항목의 설정은 2000 년 이후에 시작되

"Corresponding author, E-mail: nabk@chungbuk.ac.kr
었다고 볼 수 있다. 휘발유에 있어서 2000년부터 자 동차 배출허용 기준의 강화추세와 함께 배출 후처 리장치의 성능 및 효율에 크게 영향을 주는 ‘황함량' 이 항목에 추가되었고 대기오염의 오존 $\left(\mathrm{O}_{3} ;\right.$ Ozone $)$ 문제와 휘발성 유기화합물(VOCs; Volatile Organic Compounds) 저감을 위해 올레핀, 증기압 등이 새로 운 항목으로 추가되면서 꾸준히 강화해오고 있다.

올레핀은 대기 중으로 휘발되어 오존 형성에 기 여하며 연소시 독성이 큰 디엔화합물을 만든다. 올 레핀을 $20 \%$ 에서 $5 \%$ 로 감소시킬 때 오존형성능력 이 현저하게 줄어든다는 연구결과)에 의하면 향후 몇 년 후 경량차량의 최대 오존 기여를 $13 \sim 25 \%$ 정도 감소시킬 것으로 나타났으며, 이 효과의 $70 \%$ 는 프 로펜, 부텐 등의 저분자 올레핀의 감소에 따른 것으 로 보고되었다(Fig. 1).

연료의 올레핀은 배출가스의 올레핀과 매우 밀접 한 관계를 가지고 있다. 올레핀은 오존형성의 조건 


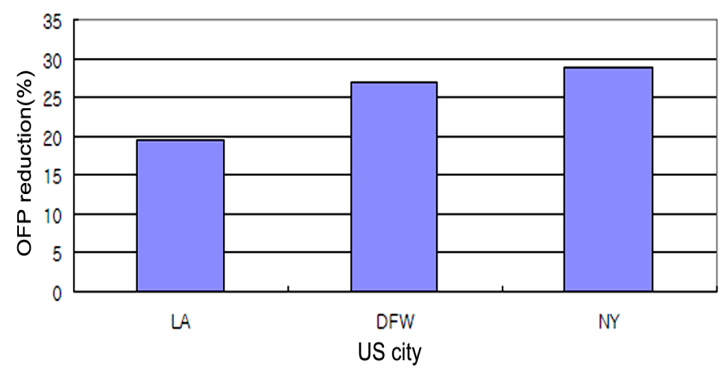

Fig. 1 OFP (Ozone Forming Potential) according to olefin content $(20 \rightarrow 5 \mathrm{vol} \%)$

에서 반응성이 매우 높기 때문에, 올레핀 함량이 낮 아질수록 배출가스의 특정 반응성도 낮아지는 방향 으로 따라간다. 독성 배출물질에 대한 올레핀의 하 나의 큰 영향은 1,3 butadiene를 줄이는 것이었다.

또 다른 연구결과)에서는 39대의 1989 1990년도 사용 중인 차량을 12 종의 연료와 함께 시험하였다. 올레핀 함량이 낮은 연료는 $\mathrm{NOx}$ 는 저감되나 $\mathrm{CO}$ 는 동등하며 $\mathrm{HC}$ 에는 영향을 미치지 않는다고 결론지 었다.

상기와 같이 선진국 등에서는 연료품질과 자동차 기술과의 상관성 연구를 통하여 분석결과를 기준설 정에 반영하고 있으나, 국내에서는 동 분야의 상관 성에 대한 체계적인 연구는 진행되고 있지 않다.

본 연구에서는 현행 휘발유 차량 엔진방식별 (MPI, GDI)로 올레핀 함량을 변화시키면서 배출특 성을 평가하여 연료 품질기준 설정에 대한 기초자 료를 확보하고자 한다.

\section{2. 실 험}

\section{1 실험 시료 및 품질분석}

자동차용 휘발유는 400 500여 가지의 화합물로 임의 조제가 어렵기 때문에 $r$ 석유 및 석유대체연료 사업법」(이하 “석대법”) 상의 품질기준을 준수시키 면서 올레핀 함량을 충족시키도록 특정 정유사에 의뢰하여 올레핀 및 방향족 함량 등을 고려하여 Table 1과 같이 조제하였다. 평가시 올레핀만의 영 향을 평가하기 위하여 방향족 함량은 19 부피 $\%$ 로 고 정하였다.

품질분석은 석대법 상의 자동차용 휘발유 품질기 준에 근거하여 각 품질항목별 한국산업규격(KS) 및
Table 1 Test fuel

\begin{tabular}{|c|c|c|c|c|}
\hline & \multicolumn{2}{|c|}{ Blending ratio (vol\%) } & \multirow{2}{*}{ Others } \\
\cline { 2 - 4 } & Fuel A & Fuel B & Fuel C & \\
\hline $\begin{array}{c}\text { Olefin } \\
\text { contents }\end{array}$ & 12 & 16 & 20 & · Aromatics : 19vol\% \\
\hline
\end{tabular}

Table 2 Gasoline quality spec. and test method

\begin{tabular}{|c|c|c|c|c|}
\hline & \multirow{2}{*}{ Property } & \multicolumn{2}{|c|}{ Spec. } & \multirow{2}{*}{ Test method } \\
\hline & & regular & Premium & \\
\hline & RON & $91 \sim 94$ & $94 \uparrow$ & KS M 2039 \\
\hline \multirow{5}{*}{$\begin{array}{l}\text { DIST } \\
\left({ }^{\circ} \mathrm{C}\right)\end{array}$} & T10 & \multicolumn{2}{|c|}{$70 \downarrow$} & KS M ISO 3405 \\
\hline & T50 & \multicolumn{2}{|c|}{$125 \downarrow$} & $"$ \\
\hline & T90 & \multicolumn{2}{|c|}{$170 \downarrow$} & $\prime \prime$ \\
\hline & FBP & \multicolumn{2}{|c|}{$225 \downarrow$} & $"$ \\
\hline & Residue (vol\%) & \multicolumn{2}{|c|}{$2.0 \downarrow$} & $"$ \\
\hline \multicolumn{2}{|c|}{$\begin{array}{l}\text { water \& sediment } \\
(\mathrm{vol} \%)\end{array}$} & \multicolumn{2}{|c|}{$0.01 \downarrow$} & KS M 2115 \\
\hline \multicolumn{2}{|c|}{$\begin{array}{l}\text { Copper corrosion } \\
\left(50^{\circ} \mathrm{C} / 3 \mathrm{~h}\right)\end{array}$} & \multicolumn{2}{|c|}{$1 \downarrow$} & KS M 2018 \\
\hline \multicolumn{2}{|c|}{$\begin{array}{l}\text { Vapor Pressure } \\
\left(37.8^{\circ} \mathrm{C}, \mathrm{kPa}\right)\end{array}$} & \multicolumn{2}{|c|}{$\begin{array}{c}\text { 44 82(S:44 65, } \\
\mathrm{W}: 44 \sim 96)\end{array}$} & KS M ISO 3007 \\
\hline \multicolumn{2}{|c|}{$\begin{array}{l}\text { Oxidation stability } \\
\text { (min) }\end{array}$} & \multicolumn{2}{|c|}{$480 \uparrow$} & KS M 2043 \\
\hline \multicolumn{2}{|c|}{$\operatorname{Gum}(\mathrm{mg} / 100 \mathrm{~mL})$} & \multicolumn{2}{|c|}{$5 \downarrow$} & KS M 2041 \\
\hline \multicolumn{2}{|c|}{ Sulfur (mg/kg) } & \multicolumn{2}{|c|}{$10 \downarrow$} & KS M 2027 \\
\hline \multicolumn{2}{|c|}{ Color } & Yellow & Green & \\
\hline \multicolumn{2}{|c|}{ Lead contents $(\mathrm{g} / \mathrm{L})$} & \multicolumn{2}{|c|}{$0.013 \downarrow$} & KS M 2402 \\
\hline \multicolumn{2}{|c|}{ Phosphorus (g/L) } & \multicolumn{2}{|c|}{$0.0013 \downarrow$} & KS M 2403 \\
\hline \multicolumn{2}{|c|}{ Aromatics (vol\%) } & \multicolumn{2}{|c|}{$24(21) \downarrow$} & KS M 2407 \\
\hline \multicolumn{2}{|c|}{ Benzene (vol\%) } & \multicolumn{2}{|c|}{$0.7 \downarrow$} & KS M 2407 \\
\hline \multicolumn{2}{|c|}{ Olefin (vol\%) } & \multicolumn{2}{|c|}{$16(19) \downarrow$} & KS M 2455 \\
\hline \multicolumn{2}{|c|}{ Oxygen (mass\%) } & \multicolumn{2}{|c|}{$0.5 \sim 2.3(\mathrm{~W}: 1.0 \sim 2.3)$} & KS M 2408 \\
\hline \multicolumn{2}{|c|}{ Methanol (mass\%) } & \multicolumn{2}{|c|}{$0.1 \downarrow$} & KS M 2408 \\
\hline
\end{tabular}

최신 규격으로 품질분석을 실시하였으며, Table 2에 품질기준 및 시험방법을 나타내었다.

\section{2 실험장치 및 방법}

\subsection{1 평가차량}

올레핀 함량에 따른 환경성 평가를 위하여 현행 의 휘발유 엔진 방식에 따라 MPI (Multi-Point Injection)과 최근 개발되어 상용화된 GDI (Gasoline Direct Injection) 방식의 차량을 각각 1 대씩 선정하여 성능을 평가하였으며, 그 제원을 Table 3 에 나타내 었다. 
Table 3 Specification of experimental vehicle

\begin{tabular}{|c|c|c|}
\hline & $\begin{array}{c}\text { GDI engine } \\
\text { equipped vehicle }\end{array}$ & $\begin{array}{c}\text { MPI engine equipped } \\
\text { vehicle }\end{array}$ \\
\hline Model Year & 2011 & 2011 \\
\hline GVW (kg) & 1,695 & 1,055 \\
\hline Transmission & $6 \mathrm{AT}$ & $4 \mathrm{AT}$ \\
\hline Displacement (cc) & 2,384 & 1,596 \\
\hline Max. Power (ps/rpm) & $185 / 6,700$ & $108 / 6,200$ \\
\hline $\begin{array}{c}\text { Max. Torque } \\
\text { (kg.m/rpm) }\end{array}$ & $24.0 / 4,900$ & $13.9 / 5,000$ \\
\hline Fuel tank (L) & 73 & 43 \\
\hline F.E. $(\mathrm{km} / \mathrm{L})$ & $10.6(\mathrm{AT})$ & $18.0(\mathrm{MT}) / 16.1(\mathrm{AT})$ \\
\hline
\end{tabular}

\subsection{2 차대동력계 및 배기가스 분석장치}

차량 성능 및 환경성 평가에 사용된 차대동력계 (Chassis Dynamometer - 4WD) 시스템은 항온항습 실, 차대동력계, Driver's Aid, 희석터널, 배출가스 분 석장치, 보조운전장치 등으로 구성된 시스템으로 국내 차량 총중량 3.5 톤 미만의 자동차에 대하여 배 출가스 및 연료소비율을 측정할 수 있도록 형식승 인된 시험장비이다. 아래 Fig. 2 에 시험에 사용된 차 대동력계 시스템 개략도를 나타내었다.

배출가스 측정 장치 $(\mathrm{MEXA}-7400 \mathrm{LE})$ 는 배출가스 중 $\mathrm{CO}, \mathrm{THC}, \mathrm{NOx}, \mathrm{CO}_{2}$ 을 분석할 수 있는 장치로서, 분석원리는 $\mathrm{CO}$ 및 $\mathrm{CO}_{2}$ 가 비분산적외선분석법(NDIR, Nondispersive Infrared), $\mathrm{THC}$ 는 열식불꽃이온화검 출기법(HFID, Heated Flame Ionization Detector), NOx 는 화학발광법(CLD, Chemiluminescence Detector)을 사용하였다.
1,3-부타디엔 등 미규제물질은 FT-IR 분광기 (spectroscopy)를 이용하여 측정하였으며 적외선 영 역 $4000 ~ 400 \mathrm{~cm}-1$ 의 영역에서 $\pm 2 \%$ 이내의 선형성을 가지며, $\mathrm{ppm}$ 단위로 농도를 연속적으로 측정하였다.

\subsection{3 시험방법 및 시험모드}

시험은 항온이 유지된 시험실 내 $\left(\right.$ 항온 $\left.25 \pm 5^{\circ} \mathrm{C}\right)$ 에 서 대기환경보전법 제 3 조제 1 호에 규정된 국내 제작 자동차 공인시험모드인 CVS-75모드 및 HWFET모 드를 사용하여 배출가스 항목 $\left(\mathrm{CO}, \mathrm{HC}, \mathrm{NOx}, \mathrm{CO}_{2}\right)$ 을 측정하였으며, 연료소비효율은 산업통상자원부 고시 제 2008-162호(자동차의 에너지소비효율 및 등급표시에 관한 규정)에 의거한 에너지소비효율 을 측정하였다.

모든 시험은 정확도를 고려하여 3 회 실시하였다. 각각의 운전조건에 따라 배출가스 $\left(\mathrm{CO}, \mathrm{THC}, \mathrm{CO}_{2}\right.$, $\mathrm{NOx})$, 연비 및 미규제 배출가스 특성 등을 측정하였다.

\section{3. 결과 및 고찰}

\section{1 연료 물성}

실험연료의 연료적 품질특성에 대한 분석은 Table 4와 같이 석대법상 품질기준 항목에 의거하여 올레핀 표준시료를 분석한 결과, 방향족은 18 19 부 피 $\%$ 이며, 올레핀은 각각 $12,16,20$ 부피 $\%$ 로 분석되 었으며, 기타 물성 항목은 석대법상 휘발유 품질기 준을 만족하였다.

연료의 분석결과, 배출가스에 영향을 주는 주요

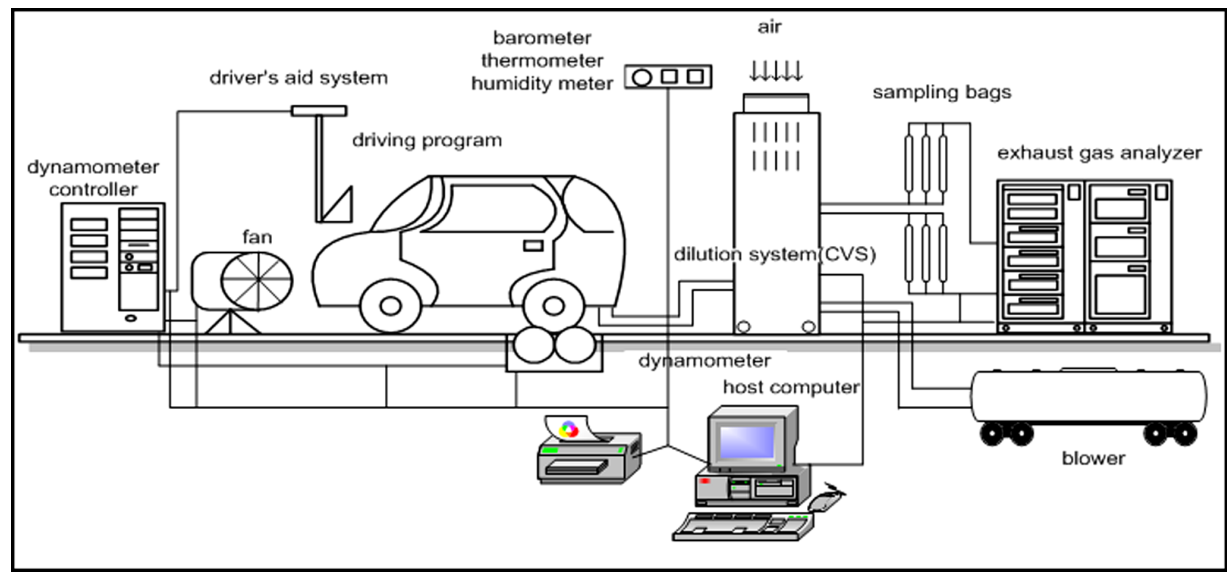

Fig. 2 Schematic diagram of gasoline vehicle emission measurement system 
Table 4 Properties of test fuels

\begin{tabular}{|l|c|c|c|c|c|}
\hline \multicolumn{1}{|c|}{ Property } & Spec. & Fuel A & Fuel B & Fuel C \\
\hline \multicolumn{2}{|c|}{ Octane No. } & $91 \sim 94$ & 91 & 91 & 91 \\
\hline \multirow{4}{*}{$\begin{array}{c}\text { DIST. } \\
\left({ }^{\circ} \mathrm{C}\right)\end{array}$} & T10 & $70 \downarrow$ & 55 & 55 & 55 \\
\cline { 2 - 6 } & T50 & $125 \downarrow$ & 84 & 81 & 78 \\
\cline { 2 - 6 } & FBP & $170 \downarrow$ & 162 & 163 & 164 \\
\hline $\begin{array}{l}\text { Copper corrosion } \\
\left(50^{\circ} \mathrm{C} / 3 \mathrm{~h}\right)\end{array}$ & $225 \downarrow$ & 200 & 200 & 198 \\
\hline $\begin{array}{l}\text { Vapor Pressure } \\
\left(37.8^{\circ} \mathrm{C}, \mathrm{kPa}\right)\end{array}$ & $44 \sim 82$ & 59 & 59 & 59 \\
\hline $\begin{array}{l}\text { Oxidation stability } \\
(\text { min) }\end{array}$ & $480 \uparrow$ & $480 \uparrow$ & $480 \uparrow$ & $480 \uparrow$ \\
\hline Gum(mg/100mL) & $5 \downarrow$ & $1 \downarrow$ & $1 \downarrow$ & $1 \downarrow$ \\
\hline Sulfur (mg/kg) & $10 \downarrow$ & 4 & 5 & 5 \\
\hline Color & Yellow & Yellow & Yellow & Yellow \\
\hline Lead contents (g/L) & $0.013 \downarrow$ & $0.001 \downarrow$ & $0.001 \downarrow$ & $0.001 \downarrow$ \\
\hline Phosphorus (g/L) & $0.0013 \downarrow$ & $0.0001 \downarrow$ & $0.0001 \downarrow$ & $0.0001 \downarrow$ \\
\hline Aromatics (vol\%) & $24(21) \downarrow$ & 18 & 19 & 18 \\
\hline Benzene (vol\%) & $0.7 \downarrow$ & 0.5 & 0.6 & 0.7 \\
\hline Olefin (vol\%) & $16(19) \downarrow$ & 12 & 16 & 20 \\
\hline Oxygen (mass\%) & $2.3 \downarrow$ & 1.9 & 1.9 & 2.0 \\
\hline Methanol (mass\%) & $0.1 \downarrow$ & $0.1 \downarrow$ & $0.1 \downarrow$ & $0.1 \downarrow$ \\
\hline
\end{tabular}

항목으로는 옥탄값의 경우 91 , 벤젠과 방향족은 3 가 지 연료 모두에서 동등한 결과값을 나타내었으며, 배출가스의 주요 증가요인으로 작용하는 황분함량 은 4 5 mg/kg으로 sulfur-free수준으로 분석되었다. 표준시료 분석결과에서 올레핀 성분만 변화됨을 알 수 있으며, 배출가스 등 측정값에서 올레핀 함량 감 소에 따른 배출가스 저감을 예측할 수 있다.

\section{2 배출특성}

올레핀 함량변화에 따른 배출가스 측정의 신뢰도 향상 및 정확도를 높이기 위하여 3 회 측정을 기본으 로 수행하나, 시험 오차값이 클 경우 반복시험 수행 하였다.

휘발유 중 올레핀 함량에 따른 규제물질별 배출 가스 특성은 Fig. 3, 4 에서와 같이 2.4L GDI 차량 및 $1.6 \mathrm{~L} \mathrm{MPI}$ 차량 모두에서 fuel C(올레핀 함량 $20 \%$ ) 연 료 대비 올레핀 함량감소에 따라 적게 배출되었다. 이러한 결과는 연료의 물성 분석결과에 의한 배출 가스 예측과 동일한 결과를 나타내었다.

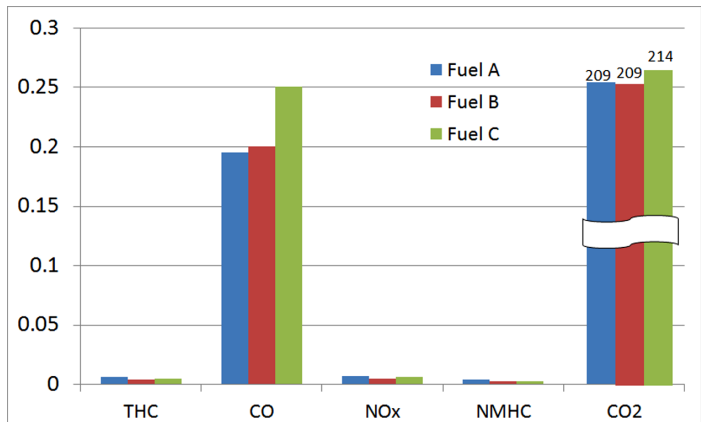

Fig. 3 Emissions $(\mathrm{g} / \mathrm{km})$ by CVS-75 mode (2.4L GDI engine equipped vehicle)

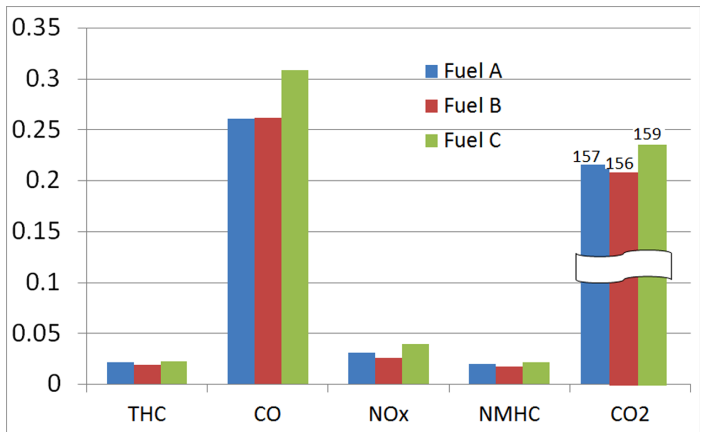

Fig. 4 Emissions $(\mathrm{g} / \mathrm{km})$ by CVS-75 mode (1.6L MPI engine equipped vehicle)

올레핀 함량 감소 $(20 \rightarrow 12$ 부피 $\%)$ 에 따른 배출가 스 평가결과, 일산화탄소 $(\mathrm{CO})$, 이산화탄소 $\left(\mathrm{CO}_{2}\right)$ 는 일정하게 감소하는 경향을 나타내었으나, 그 외의 배출가스는 경향성을 확인할 수 없었다. 메탄 $\left(\mathrm{CH}_{4}\right)$ 및 비메탄탄화수소(NMHC)는 올레핀 함량이 12 부 피 $\%, 20$ 부피 $\%, 16$ 부피 $\%$ 의 순으로 증가하는 경향이 며, 전탄화수소(THC) 및 질소산화물 $(\mathrm{NOx})$ 는 20 부 피 $\%, 12$ 부피 $\%, 16$ 부피 $\%$ 의 순으로 증가하는 경향으 로 평가되었다.

2.4L GDI 방식 차량은 올레핀 함량에 따라 $\mathrm{CO}$, $\mathrm{CO}_{2}$ 의 증가경향을 나타내었으나, $\mathrm{THC}, \mathrm{NOx}, \mathrm{CH}_{4}$, $\mathrm{NMHC}$ 와 관련하여 증감의 상관성은 나타나지 않았 다. CRC (Coordinating Research Council)의 연구보고 서 $^{5}$ 에 의하면 올레핀 함량 증가에 따라 $\mathrm{CO}$ 가 증가 하는 것으로 보고되고 있으며, 본 평가에서도 올레핀 증가 $(12 \rightarrow 20 \%)$ 에 따라 $\mathrm{CO}(\mathrm{CVS}-75$ 모드 $0.06 \mathrm{~g} / \mathrm{km}$, HWFET 모드 $0.07 \mathrm{~g} / \mathrm{km}$ )가 증가하였다. 또한 CRC 및 다양한 연구보고서,7)에 의하면 올레핀 증가는 
$\mathrm{NOx}$ 의 감소와 $\mathrm{HC}$ 의 증가를 발생시키는 것으로 보 고되고 있으나, 본 평가에서는 이러한 경향을 확인 할 수 없었다.

$1.6 \mathrm{~L} \mathrm{MPI}$ 방식 차량에서는 올레핀 함량에 따라 $\mathrm{CO}(\mathrm{CVS}-75$ 모드 $0.05 \mathrm{~g} / \mathrm{km}, \mathrm{HWFET}$ 모드 $0.04 \mathrm{~g} / \mathrm{km})$ 가 증가하는 경향을 나타내었으나, $\mathrm{CO}_{2}, \mathrm{THC}, \mathrm{NOx}$, $\mathrm{CH}_{4}, \mathrm{NMHC}$ 와 관련하여 증감의 상관성을 확인할 수 없었다.

이러한 배출가스 저감 요인으로는 휘발유 구성성 분 중 이중결합을 지니는 올레핀은 일반적으로 파 라핀 성분대비 연소과정에서 반응성이 좋으나, 올 레핀 저감에 따라 올레핀을 대체하는 파라핀 성분 이 완전연소가 유도되어 $\mathrm{CO}$ 등의 배출가스가 낮게 된다.

\subsection{1 엔진기술별 배출가스 저감효율}

엔진기술별 배출가스 저감효율은 Fig. 5, 6에서와 같이 일산화탄소 $(\mathrm{CO})$, 전탄화수소(THC) 등 모든 배 출가스 항목에서 $\mathrm{GDI}$ 엔진 탑재차량의 배출가스 저 감효율이 보다 높게 나타났다.

엔진기술의 발달에 따른 배출가스 저감 효과는 시험차량 2 대의 배기량 및 모델이 상이하여 직접적 인 비교는 불가하나 간접적인 저감효과는 비교가 가능하다고 판단된다. 직접분사방식을 적용한 자동 차가 간접분사방식 보다 배출가스가 적 게 나타나는 것으로 나타났다.

따라서 차량의 마일리지 및 촉매의 상태에 따라 상이하기 때문에 일반화되기는 어려우나, 간접분사 방식 차량이 점차 사라지고 이미 양산되고 있는 직

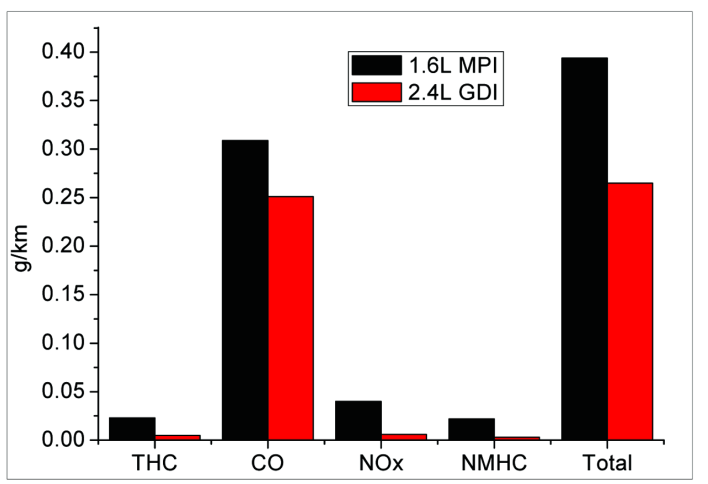

Fig. 5 Emissions of GDI engine compared with MPI engine in Fuel C (olefin contents 20\%)

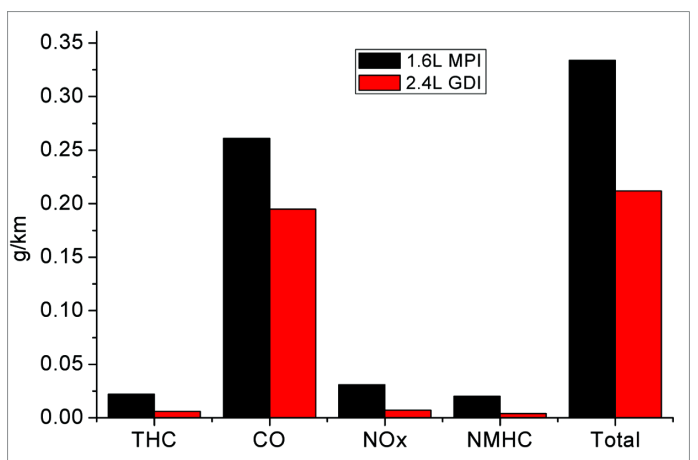

Fig. 6 Emissions of GDI engine compared with MPI engine in Fuel A (olefin contents 12\%)

접분사 방식 차량이 늘어날 수 록 배출가스 저감효 과는 더 커질 것으로 예상할 수 있다.

\subsection{2 미규제물질 배출특성}

Table 5,6에 올레핀 함량에 따른 미규제물질 분석 결과를 나타내었다. $2.4 \mathrm{~L} \mathrm{GDI}$ 차량의 경우, 아세틸 렌(Acetylene), 1,3-부타디엔(1,3 butadiene)은 미량 감소하였으나, 포름알데히드(Formaldehyde), 자일 렌(Xylene), 벤젠 (Benzene), 톨루엔(Toluene)은 동등 수준으로 평가되었으며, 1.6L MPI 차량에서는 포름 알데히드, 벤젠, 아세틸렌은 미량 증가하였으나 톨 루엔, 자일렌, 1,3 부타디엔은 표준편차내 동등수준 의 결과로 평가되었다. 올레핀은 열에 불안정하여 엔진내 검 형성 및 퇴적물을 일으키며 연소생성물 로는 디엔(Diene)이 형성된다. 그러나, 2.4L GDI 차 량에서의 1,3 부타디엔 감소 및 1.6L MPI 차량에서 의 동등수준의 결과로 이러한 상관성을 확인할 수 없었다.

\subsection{3 연료소비효율}

올레핀 함량변화에 따른 연료소비효율은 산업통 상자원부 고시 '자동차의 에너지소비효율 및 등급 표시엔 관한 규정'에 의거하여 복합 에너지소비효 율로 아래 식을 사용하여 산출하였다.

$$
\begin{aligned}
& \text { - 복합 } \\
& \text { 에너지 } \\
& \text { 소비효율 } \\
& (\mathrm{km} / \ell)
\end{aligned}
$$

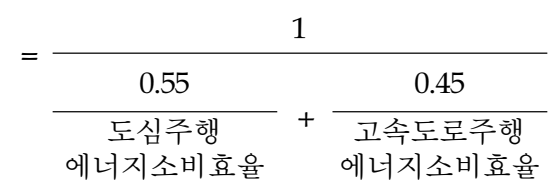

연료소비효율 측정결과, Fig. 7에서와 같이 연료 
Table 5 Unregulated emissions test results of 2.4L GDI equipped vehicle

\begin{tabular}{|c|c|c|c|c|c|c|}
\hline & $\begin{array}{c}\text { Formaldehyde } \\
(\mathrm{HCHO})\end{array}$ & $\begin{array}{c}\text { Benzene } \\
\left(\mathrm{C}_{6} \mathrm{H}_{6}\right)\end{array}$ & $\begin{array}{c}\text { Toluene } \\
\left(\mathrm{C}_{7} \mathrm{H}_{8}\right)\end{array}$ & $\begin{array}{l}\text { Xylene } \\
\left(\mathrm{C}_{8} \mathrm{H}_{10}\right)\end{array}$ & $\begin{array}{c}\text { 1-3Butadiene } \\
\left(\mathrm{C}_{4} \mathrm{H}_{6}\right)\end{array}$ & $\begin{array}{c}\text { Acetylene } \\
\left(\mathrm{C}_{2} \mathrm{H}_{2}\right)\end{array}$ \\
\hline Fuel A & $\begin{array}{c}0.350 \\
(0.037)\end{array}$ & $\begin{array}{c}1.582 \\
(0.195)\end{array}$ & $\begin{array}{c}1.015 \\
(0.042)\end{array}$ & $\begin{array}{c}0.469 \\
(0.034)\end{array}$ & $\begin{array}{c}0.583 \\
(0.021)\end{array}$ & $\begin{array}{c}0.659 \\
(0.118)\end{array}$ \\
\hline Fuel B & $\begin{array}{c}0.367 \\
(0.015) \\
\end{array}$ & $\begin{array}{c}1.143 \\
(0.052)\end{array}$ & $\begin{array}{c}0.017 \\
(0.006)\end{array}$ & $\begin{array}{c}0.453 \\
(0.046)\end{array}$ & $\begin{array}{c}0.692 \\
(0.029)\end{array}$ & $\begin{array}{c}0.391 \\
(0.036)\end{array}$ \\
\hline Fuel C & $\begin{array}{c}0.233 \\
(0.072)\end{array}$ & $\begin{array}{l}1.052 \\
(0.283)\end{array}$ & $\begin{array}{c}0.107 \\
(0.031)\end{array}$ & $\begin{array}{c}0.524 \\
(0.022)\end{array}$ & $\begin{array}{c}0.742 \\
(0.018)\end{array}$ & $\begin{array}{c}0.332 \\
(0.013)\end{array}$ \\
\hline
\end{tabular}

주) ( ) 안은 표준편차임.

Table 6 Unregulated emissions test results of 1.6L MPI equipped vehicle

\begin{tabular}{|c|c|c|c|c|c|c|}
\hline & $\begin{array}{c}\text { Formaldehyde } \\
(\mathrm{HCHO})\end{array}$ & $\begin{array}{c}\text { Benzene } \\
\left(\mathrm{C}_{6} \mathrm{H}_{6}\right)\end{array}$ & $\begin{array}{c}\text { Toluene } \\
\left(\mathrm{C}_{7} \mathrm{H}_{8}\right)\end{array}$ & $\begin{array}{c}\text { Xylene } \\
\left(\mathrm{C}_{8} \mathrm{H}_{10}\right)\end{array}$ & $\begin{array}{c}\text { 1-3Butadiene } \\
\left(\mathrm{C}_{4} \mathrm{H}_{6}\right)\end{array}$ & $\begin{array}{c}\text { Acetylene } \\
\left(\mathrm{C}_{2} \mathrm{H}_{2}\right)\end{array}$ \\
\hline \multirow{2}{*}{ Fuel A } & 0.261 & 0.366 & 0.116 & 0.379 & 0.639 & 0.513 \\
& $(0.035)$ & $(0.058)$ & $(0.041)$ & $(0.062)$ & $(0.069)$ & $(0.016)$ \\
\hline \multirow{2}{*}{ Fuel B } & 0.314 & 0.840 & 0.081 & 0.447 & 0.671 & 0.474 \\
& $(0.006)$ & $(0.015)$ & $(0.021)$ & $(0.048)$ & $(0.042)$ & $(0.006)$ \\
\hline \multirow{2}{*}{ Fuel C } & 0.383 & 0.932 & 0.208 & 0.479 & 0.769 & 1.071 \\
& $(0.030)$ & $(0.017)$ & $(0.074)$ & $(0.068)$ & $(0.030)$ & $(0.005)$ \\
\hline
\end{tabular}

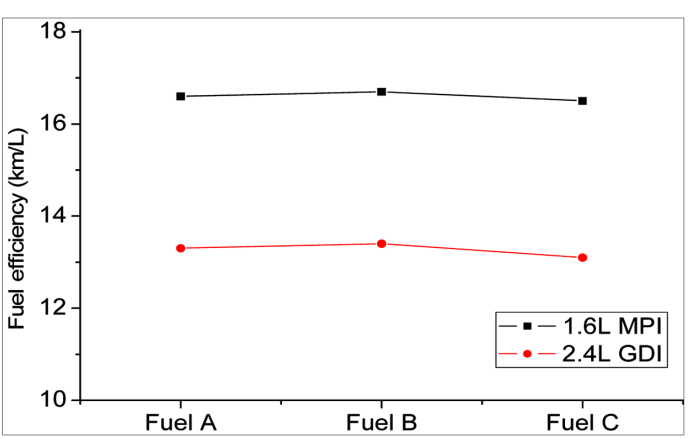

Fig. 7 Fuel efficiency test results by combined mode

의 기본적인 품질은 변화되지 않았으며, 옥탄가, 발 열량 등 연비에 기여하는 연료물성 차이가 없기 때 문에 3 가지 연료에서 연료소비효율의 차이는 없으 며, 동등수준으로 평가되었다.

\section{3 올레핀 함량에 따른 배출가스 상관성}

올레핀 함량변화에 따른 배출가스 상관성 연구는 미국 등의 오토오일프로그램(AQIRP, Air Quality Improvement Research Program)에서 체계적인 연구 를 수행하여 왔다. 동 연구결과 ${ }^{8}$ 에 따르면, 올레핀 함량을 $15 \%(20 \rightarrow 5 \%)$ 저감시 $\mathrm{HC}$ 는 $7.1 \%$ 증가, $\mathrm{NOx}$ 는 $6.1 \%$ 저감, 1,3 부타디엔은 $31.6 \%$ 저감된다는 결 과를 보고하였다.
Table 7 Effects of reducing olefin contents

\begin{tabular}{|c|c|c|c|}
\hline \multirow{2}{*}{} & \multirow{2}{*}{$\begin{array}{c}\text { AQIRP } \\
\text { results }\end{array}$} & \multicolumn{2}{|c|}{ Olefin change $20 \Rightarrow 12 \%$} \\
\cline { 3 - 4 } & +7.1 & -20 L GDI & $1.6 \mathrm{~L}$ MPI \\
\hline $\mathrm{HC}$ & $+1.5(\mathrm{NS})$ & -22 & $-8(\mathrm{NS})$ \\
\hline $\mathrm{CO}$ & -6.1 & $+17(\mathrm{NS})$ & -17 \\
\hline NOx & -31.6 & -21 & -17 \\
\hline 1,3 Butadiene & & $+5 S)$ \\
\hline Formaldehyde & $+1.3(\mathrm{NS})$ & $+50(\mathrm{NS})$ & $-32(\mathrm{NS})$ \\
\hline $\mathrm{CO}_{2}$ & & -2 & -1 \\
\hline
\end{tabular}

1) Percent Change in Emissions $20 \% \rightarrow 5 \%$ Olefins

본 평가에서는 Table 7에서 나타낸 바와 같이 올 레핀 $8 \%$ 저감에 따라 $\mathrm{HC} 820 \%$ 저감, $\mathrm{CO}$ 는 $15 \sim 22 \%$ 저감, $\mathrm{NOx}$ 는 $+17 \sim-17 \%, 1,3$ 부타디엔은 $17 \sim 21 \%$ 저감으로 약간 상이한 결과가 도출되었다. 여기서 인용된 AQIRP 데이터는 1989년식의 기화기 방식 차량을 대상으로 한 평가이며, 본 평가는 MPI 및 GDI 엔진 탑재차량을 대상으로 직접적인 비교는 어렵지만, 올레핀 감소에 따라 1,3 부타디엔이 약 $20 \%$ 이상 저감되는 공통적인 결과가 도출되었다. 또한, 이산화탄소 배출량도 $11 \%$ 저감되어 온실가 스 저감에도 기여할 것으로 판단된다.

여기서, $\mathrm{AQIRP}$ 의 연구결과와 비교하여 $\mathrm{HC}, \mathrm{NOx}$ 및 포름알데히드는 시험차종이 제한적이고 배출량 도 극소량이기 때문에 시험결과의 정확성을 확인하 
기는 어려운 측면이 있었다.

이에 따라, 본 평가는 2종류의 엔진 탑재차량만을 대상으로 수행한 것으로 정책의 기초자료에는 문제 가 없을 것으로 예상되나 정확한 데이터 확보차원 에서 추가적인 연구가 필요할 것으로 사료된다.

\section{4. 결 론}

올레핀 함량별 배출가스 특성을 파악하기 위하여 올레핀 함량에 따른 시료 3종 $(12,16,20 \%)$ 및 2종의 평가차량(2.4L GDI방식, $1.6 \mathrm{~L} \mathrm{MPI방식)으로} \mathrm{배출가}$ 스 특성시험을 수행한 결과 다음과 같은 결과를 얻 을 수 있었다.

1) 올레핀 함량 감소 $(20 \rightarrow 12$ 부피\%)에 따른 배출가 스 평가결과, 일산화탄소 $(\mathrm{CO})$, 이산화탄소 $\left(\mathrm{CO}_{2}\right)$ 는 일정하게 감소하는 경향을 나타내었으나, 그 외의 배출가스는 경향성을 확인할 수 없었다.

2) 올레핀 함량변화는 연료소비효율에 큰 영향을 미치지 않았다.

$3)$ 일산화탄소 $(\mathrm{CO})$, 전탄화수소(THC) 등 모든 배 출가스 항목에서 GDI 엔진 탑재차량의 배출가 스 저감효율이 보다 높게 나타났다.

4) 1,3 부타디엔의 경우, $2.4 \mathrm{~L} \mathrm{GDI}$ 차량에서는 감소 되었으나, $1.6 \mathrm{~L} \mathrm{MPI} \mathrm{차량에서의} \mathrm{동등수준의} \mathrm{결}$ 과가 도출되었으며, 다른 미규제물질은 이러한 상관성을 확인할 수 없었다.

\section{References}

1) Clean Air Act, Ministry of Environment, 2013.

2) K. R. Cho, The Trends of Exhaust Emission
Standard for Gasoline Passenger Cars, Auto Journal, KSAE, Vol.30, No.2, pp.125-129, 2008.

3) C. H. Schleyer, W. J. Koehl, W. R. Leppard, A. M. Dunker, G. Yarwood, J. P. Cohen and A. K. Pollack, "Effect of Gasoline Olefin Composition on Predicted Ozone in 2005/2010 - Auto/Oil Air Quality Improvement Research Program," SAE 940579, 1994.

4) S. Mayotte, V. Rao, C. Lindhjem and M. Sklar, "Reformulated Gasoline Effects on Exhaust Emissions: Phase II: Continued Investigation of the Effects of Fuel Oxygenate Content, Oxygenate Type, Volatility, Sulfur, Olefins and Distillation Parameters," SAE 941974, 1994.

5) CRC Annual Report, Coordinating Research Council, 2009-2012.

6) A. M. Hochhauser, J. D. Benson, V. Burns, R. A. Gorse, W. J. Koehl, L. J. Painter, B. H. Rippon, R. M. Reuter and J. A. Rutherford, "The Effect of Aromatics, MTBE, Olefins and T90 on Mass Exhaust Emissions from Current and Older Vehicles - The Auto/Oil Air Quality Improvement Research Program," SAE 912322, 1991.

7) R. Stradling, R. Bazzani, S. D. Bjordal, P. Schmelzle, G. Wolff, N. Thompson, D. Rickeard, P. M. Martinez, P. Scorletti and P. J. Zemroch, "Fuel Effects on Regulated Emissions from Modern Gasoline Vehicles," SAE 2004-01-1886, 2004.

8) AQIRP Final Report, Air Quality Improvement Research Program, 1997. 